\title{
Identification of a high risk subgroup of patients with silent ischaemia after myocardial infarction: a group for early therapeutic revascularisation?
}

\author{
Mark de Belder, Douglas Skehan, Charles Pumphrey, Bilal Khan, Stephen Evans,
} Martin Rothman, Peter Mills

\begin{abstract}
Asymptomatic ("silent") ischaemia has been shown to be of prognostic significance in patients with stable and unstable angina and more recently in patients recovering after myocardial infarction. No therapeutic regimen has yet been shown to improve the prognosis of patients with silent ischaemia after infarction, which can be found in as many as a third of these patients. Attempts to achieve therapeutic revascularisation in all these patients may be undesirable, but early revascularisation could be especially beneficial in some selected high risk patients. Two hundred and fifty consecutive clinically stable survivors of myocardial infarction who had predischarge submaximal exercise tests were followed up for a year. Silent ischaemia was found in $27 \%$ of these patients; $15 \%$ had symptomatic ischaemia. Patients with a positive exercise test were prescribed a $\beta$ blocker before discharge. Mortality in patients with silent $(9 \cdot 4 \%)$ and symptomatic $(5 \cdot 4 \%)$ ischaemia in the first year after infarction was not significantly different. Patients with symptomatic ischaemia were more likely to have undergone coronary artery bypass grafting in the first year. Patients with silent ischaemia were, however, significantly more likely to die than patients with a negative exercise test (relative odds 12:1). Patients with silent ischaemia and an abnormal blood pressure response or who could not complete a submaximal exercise protocol were at particularly high risk, being 32 times more likely to die than those with a negative test $(95 \%$ confidence interval from $3 \cdot 3$ to 307 times more likely). First year mortality in this group was $22 \%$. The benefits of therapeutic revascularisation in this high risk group need to be studied.
\end{abstract}

Silent ischaemia has been recognised since early this century ("angina sine dolore") ${ }^{1}$ It occurs when there is objective evidence of myocardial ischaemia without symptoms. Such evidence is usually the presence of ST segment changes, detected during either exercise ${ }^{2-4}$ or ambulatory electrocardiograms, ${ }^{5-7}$ or abnormalities seen during thallium scintigraphy. ${ }^{89}$ Silent ischaemia has been studied in patients with stable and unstable angina $a^{10-12}$ and, more recently, in selected patients after myocardial infarction. ${ }^{81314}$ These studies suggested that silent ischaemia after infarction is associated with an adverse prognosis and is detectable in as many as a third of patients after infarction. Many patients who die in the first year do so suddenly. Evidence in growing that sudden death after infarction is related to a new ischaemic event more often than has been realised. ${ }^{15}$ Therapeutic revascularisation of all patients with evidence of ischaemia soon after infarction may improve the survival of this group, but this would make enormous demands on currently available services and may be undesirable for patients at lower risk. We therefore undertook this study to see whether we could identify a group of patients with silent ischaemia who were at particularly high risk and who might benefit from early attempts at revascularisation. We studied only those who were clinically stable seven days after an infarct, because those with complicated early courses had already identified themselves as being at higher risk; the clinical and angiographic characteristics of these patients were reported elsewhere. ${ }^{16}$

\section{Patients and methods}

We studied $302(254(84 \%)$ male and $48(16 \%)$ female; mean (SD) age $54(7 \cdot 3)$ years) consecutive patients aged $\leqslant 65$ who were clinically stable seven days after myocardial infarction. We used conventional criteria to diagnose $Q$ wave and non- $Q$ wave myocardial infarction and define anterior and inferior infarction. ${ }^{16}$ Forty patients were excluded: 10 who were unable to perform the exercise test, four with left bundle branch block, four patients with other medical conditions that carried an adverse prognosis, one patient in whom unstable angina developed during the first 7 days, one patient with previous coronary artery surgery, one patient in whom atrial flutter developed on the exercise test, and 19 patients who were not given an exercise test because of administrative error. An early submaximal 
exercise test was therefore undertaken by 262 patients. No $\beta$ blockers had been prescribed for 36 hours and digoxin had been stopped at least 7 days before the exercise test.

\section{EXERCISE TEST PROTOCOL}

Patients were exercised using the second and third stages of the modified Bruce protocol. The median interval from infarction to the exercise test was 11 days (interquartile range 912). Cuff systolic blood pressure measurements and a 12 lead electrocardiogram were recorded before the test, at the end of each 3-minute stage; and 2, 5, and 10 minutes into the recovery phase. The test was stopped early if there was severe angina pectoris, severe dyspnoea, fatigue or ataxia, ST depression $\geqslant 5 \mathrm{~mm}$ $80 \mathrm{~ms}$ after the J point, or increased ventricular extrasystoles ( $\geqslant 10 / \mathrm{min}$ or triplets). Predetermined criteria were set to define "positive" and "negative" tests: (a) development of angina pectoris; (b) development of horizontal or down-sloping ST depression $\geqslant 1 \mathrm{~mm}, 80 \mathrm{~ms}$ after the J point; (c) inappropriate blood pressure response defined as failure of the systolic blood pressure to rise by $\geqslant 10 \mathrm{~mm} \mathrm{Hg}$ - or having risen, to fall again by $\geqslant 10 \mathrm{~mm} \mathrm{Hg}$; $(d)$ inability to complete the exercise test because of severe dyspnoea, fatigue, or ataxia; and (e) development of a ventricular extrasystolic rate that was $\geqslant 6$ beats higher than the count on the resting pre-exercise electrocardiogram, or the development of ventricular triplets.

GROUP UNDERGOING CARDIAC CATHETERISATION Cardiac catheterisation was performed on 123 of 139 patients with a positive exercise test at a median of 21 (interquartile range 16-31) days after infarction. The remaining 16 did not undergo catheterisation: because of early death (four), refusal (five), incorrect reporting of the exercise test as negative (four)_-in each case an inappropriate blood pressure response had been overlooked, or administrative error (three). During cardiac catheterisation we measured several variables ${ }^{16}$; these included a left ventricular regional wall motion score based on that of the Coronary Artery Surgery Study, ${ }^{17}$ the number of vessels with a stenosis of $>50 \%$ of the diameter, an overall coronary artery score (a high score reflecting more extensive disease), and a score to reflect the supply of collateral vessels to the infarct territory.

\section{FOLLOW UP}

Patients with a positive exercise test were all prescribed a $\beta$ blocker (sotalol) (unless contraindicated) 1-2 days before discharge in a dose sufficient to reduce the resting heart rate to $\leqslant 60$ beats $/ \mathrm{min}$. The development of angina was treated with the addition of nitrates or calcium channel blockers, and coronary artery surgery was offered for angina not controlled with medication or if we believed that this would improve the prognosis based on arteriographic criteria. ${ }^{1819}$ Treatment for the "negative" group was not standardised. Follow up data were collected for one year after infarction. Of the 262 patients who performed the exercise test, 16 were lost to follow up: six from the positive group and 10 from the negative group. Six of the exercise tests could not be analysed because the recordings were lost; of these, five had been reported as negative and one as positive. Follow up on these six was complete. There were thus 240 patients with interpretable exercise tests and complete follow up. Of the 16 patients lost to follow up, six also had missing exercise tests at the time of analysis. There were, therefore, 250 welldocumented exercise tests.

\section{STATISTICAL ANALYSIS}

Data were analysed with the SPSS/PC+ program on a Sperry PC/IT computer. Unordered categorical variables were compared by $\chi^{2}$ analysis with Yates's correction as appropriate. Means were compared by analysis of variance. Likelihood ratios were calculated where appropriate. ${ }^{20}$

\section{Results}

INCIDENCE AND INTERRELATIONS OF ST SEGMENT DEPRESSION AND ANGINA (TABLE 1)

Of the 104 patients in whom ST segment depression developed, 67 (64\%) had no symptoms while angina developed in $37(36 \%)$. Those with silent ischaemia accounted for $27 \%$ of the 250 patients with well-documented exercise tests after infarction. Forty six $(18 \%)$ had ST segment depression as the only abnormality on exercise. Twenty three patients had a positive exercise test on the basis of criteria other than those used to identify these groups. A total of 123 patients had negative tests.

\section{CLINICAL OUTCOME (TABLES 2 AND 3)}

Six patients with silent ischaemia died-three suddenly, one after further myocardial infarction, and one in intractable heart failure; the circumstances surrounding the death of the sixth patient were not known (table 2). Two patients with angina and one patient with a negative exercise test died suddenly. The first year mortality of the patients excluded from the exercise protocol was $19 \%$ and that of the patients with positive exercise tests on criteria other than angina or ST depression was $26 \%$ (six patients).

Patients with silent ischaemia were 12 times more likely to die in the first year than patients with a negative exercise test $(p=0.005)(95 \%$ confidence intervals from two to 65 times more likely to die) (table 3). They were nearly twice as likely to die as those with angina, though the difference was not statistically significant $(95 \%$ confidence interval for the difference between the two groups from $6 \%$ better in the group with silent ischaemia to $14 \%$ better in the group with angina). Patients with angina were,

\section{Table 1 Patient study groups}

\begin{tabular}{llll}
\hline Groups & $\begin{array}{l}\text { Silent } \\
(n=67)\end{array}$ & $\begin{array}{l}\text { Symptomatic } \\
(n=37)\end{array}$ & $\begin{array}{l}\text { Negative } \\
(n=123)\end{array}$ \\
\hline $\begin{array}{l}\text { Angina } \\
\begin{array}{l}\text { ST segment } \\
\text { depression }\end{array}\end{array}$ & - & + & - \\
\hline
\end{tabular}


Table 2 Characteristics of patients with silent ischaemia who died

\begin{tabular}{|c|c|c|c|c|c|c|c|c|c|c|c|c|}
\hline \multirow[b]{2}{*}{ Case } & \multirow[b]{2}{*}{ Sex } & \multirow[b]{2}{*}{ Age } & \multirow[b]{2}{*}{$\begin{array}{l}\text { Risk } \\
\text { factors }\end{array}$} & \multirow[b]{2}{*}{$\begin{array}{l}\text { Prev } \\
\text { MI }\end{array}$} & \multirow[b]{2}{*}{$\begin{array}{l}\text { Infarct } \\
\text { site }\end{array}$} & \multirow{2}{*}{$\begin{array}{l}\text { Qor } \\
\text { non- } Q \\
\text { wave }\end{array}$} & \multirow[b]{2}{*}{ Other exercise test features } & \multicolumn{4}{|c|}{ Angiographic features } & \multirow[b]{2}{*}{$\begin{array}{l}\text { Mode/time } \\
\text { of death }\end{array}$} \\
\hline & & & & & & & & $\begin{array}{l}\text { LV } \\
\text { score }\end{array}$ & $\begin{array}{l}\text { CA } \\
\text { score }\end{array}$ & $\begin{array}{l}\text { No. } \\
V D\end{array}$ & Colls & \\
\hline 1 & $\mathbf{M}$ & 56 & $\mathrm{DM}$ & - & Anterior & $\mathbf{Q}$ & $\begin{array}{l}\text { Abnormal BP response, ECG } \\
\text { recovery }>5 \mathrm{~min}\end{array}$ & 30 & 35 & 4 & 3 & $\begin{array}{l}\mathrm{MI} / 10 \\
\text { mnth }\end{array}$ \\
\hline 2 & $\mathbf{M}$ & 61 & Smoker & - & Anterior & $\mathbf{Q}$ & $\begin{array}{l}\text { Test }(6 \mathrm{~min}) \text { not completed, ST } \\
\text { segment elevation, } 5 \mathrm{~mm} \text { ST } \\
\text { depression, ECG recovery }>5 \\
\text { min }\end{array}$ & 33 & 22 & 1 & 2 & $\mathrm{SD} / 5 \mathrm{mnth}$ \\
\hline 3 & $\mathbf{M}$ & 56 & $\begin{array}{l}\text { Smoker, HT, } \\
\text { DM }\end{array}$ & - & Inferior & Non-Q & $\begin{array}{l}\text { Resting ST segment depression } \\
0.1 \mathrm{mV}, \text { ECG recovery } 2-5 \mathrm{~min}\end{array}$ & $25 \mathrm{An}$ & 28 & 2 & 0 & CCF $/ 2$ \\
\hline 4 & $\mathbf{M}$ & 55 & Smoker, FH & - & Inferior & $\mathbf{Q}$ & $\begin{array}{l}\text { Resting ST segment depression } \\
0 \cdot 1 \mathrm{mV} \text {, ST segment elevation, } \\
\text { ECG recovery } 2-5 \mathrm{~min}\end{array}$ & 22 & 16 & 2 & 0 & $\mathrm{SD} / 9$ mnth \\
\hline 5 & $\mathbf{M}$ & 46 & Smoker & - & Inferior & Non-Q & $\begin{array}{l}\text { Abnormal BP response, ECG } \\
\text { recovery }>5 \mathrm{~min}\end{array}$ & 21 & 38 & 4 & 4 & Unknown/ 1 mnth \\
\hline 6 & $\mathbf{M}$ & 60 & Smoker, FH & + & Anterior & Q & $\begin{array}{l}\text { Test }(6 \mathrm{~min}) \text { not completed, ST } \\
\text { segment elevation, ECG } \\
\text { recovery }>5 \text { min }\end{array}$ & 26 & 18 & 2 & 3 & $\mathrm{SD} / 2 \mathrm{mnth}$ \\
\hline
\end{tabular}

An, aneurysm; BP, blood pressure; CA, coronary artery; CCF, congestive cardiac failure; Colls, collateral score; DM, diabetes mellitus; ECG recovery time, time taken for ST segment depression developing during exercise to return to level of resting ECG before test; FH, positive family history; HT, hypertension; LV, left ventricular; MI, myocardial infarction; SD, sudden death; ST segment elevation, elevation in leads reflecting infarct; VD, vessels diseased.

however, more likely to have undergone coronary artery bypass surgery $(30 \% v 14 \%$ of those with silent ischaemia $(p=0 \cdot 06))$, probably because they were more likely to have complained of angina in the first year after infarction $(79 \% v 41 \%, \mathrm{p}<0.005)$.

To refine the risk stratification of patients with silent ischaemia they were separated into two subgroups-those with and those without at least one of the other criteria that had been used to define a positive exercise test. Four of the six patients who died in the first year had shown an additional feature (an abnormal blood pressure response, patients 1 and 5; or an inability to complete the submaximal protocol, patients 2 and 6) (table 2). A high risk group of patients with silent ischaemia was thus identified (table 4); these patients were more likely to die than any of the other groups. The "highrisk" patients with silent ischaemia were not only 32 times more likely to die than the patients with negative exercise tests $(95 \%$ confidence interval from 3.3 to 307 times more likely), but they were 6.5 times more likely to die than the "low risk" patients with silent ischaemia ( $95 \%$ confidence interval from 1.2 to 33 times more likely), and five times more likely to die than those with symptomatic ischaemia (95\% confidence interval from 0.9 to 27 times as likely).

\section{SUBGROUP ANALYSES:ALLOWANCE FOR "RECIPROCAL" CHANGES}

In some patients the development of ST depression might have been a reciprocal change in response to the development of ST elevation

Table 3 Clinical outcome in the first year after infarction in patients with silent and symptomatic ST depression

\begin{tabular}{|c|c|c|c|}
\hline & $\begin{array}{l}\text { Silent } \\
\left(n=64^{\star}\right)\end{array}$ & $\begin{array}{l}\text { Symptomatic } \\
(n=37)\end{array}$ & $\begin{array}{l}\text { Negative } \\
\left(n=113^{\star}\right)\end{array}$ \\
\hline Dead (no,".) & $6 \quad(9 \cdot 4)$ & $2(5 \cdot 4)$ & $(0 \cdot 9)$ \\
\hline Relative odds & 12 & $6 \cdot 4$ & $i$ \\
\hline Angina (no, "..) & $26(41)$ & $29(79)$ & (27) \\
\hline Relative odds & $1 \cdot 7$ & $9 \cdot 6$ & 1 \\
\hline Coronary artery bypass grafting (no, " ") & 9 (14) & $11(30)$ & $(2 \cdot 7)$ \\
\hline Relative odds & $5 \cdot 7$ & 16 & 1 \\
\hline Myocardial infarction (no, ".) & $3(4 \cdot 7)$ & $(2 \cdot 7)$ & $(2 \cdot 7)$ \\
\hline Relative odds & 1.7 & $i$ & 1 \\
\hline Left ventricular failure (no, ".) & $5(7 \cdot 8)$ & $1(2 \cdot 7)$ & $(2 \cdot 7)$ \\
\hline Relative odds & 3 & 1 & 1 \\
\hline
\end{tabular}

^Some lost to follow up. in the infarct territory on exercise. In two studies of post-infarct patients this feature typified a group with extensive left ventricular damage. ${ }^{21}{ }^{22}$ This factor may account for the increased mortality in the group with silent ischaemia (as well as the group with symptoms) compared with those with a negative test. We performed further analyses to investigate this possibility. These showed that the increased mortality was not confined to those with ST segment elevation; this applied for all patients with ST depression, whether this was silent or symptomatic. Of the 67 patients with silent ischaemia, 28 developed ST segment elevation in the territory and three $(11 \%)$ died in the first year. Of the 39 patients without ST elevation, three $(7 \cdot 7 \%)$ died.

\section{COMPARISON OF CLINICAL AND ANGIOGRAPHIC} CHARACTERISTICS OF PATIENT GROUPS (TABLE 5) We compared the clinical features in all the groups and the exercise responses and angiographic features in the groups with silent ischaemia and angina.

History and 12 lead electrocardiogram (table 5) The only significant difference between the groups was that $25 \%$ of patients with silent ischaemia had a history of hypertension compared with $11 \%$ of those with a negative test $(p=0.008)$. Of the total number of patients with a history of hypertension, $34 \%$ had a resting ST segment change of $\geqslant 0.05 \mathrm{mV}$ compared with $17 \%$ of those who did not have hypertension $(p<0.02)$. Of all patients with resting $S T$ segment depression $\geqslant 0.05 \mathrm{mV}$, $72 \%$ developed at least $0 \cdot 1 \mathrm{mV}$ of further ST segment depression on exercise compared with $32 \%$ of those without resting changes ( $p<$ 0.001 ).

There was no difference in the distribution of sites of infarction between patients with silent ischaemia and symptomatic ischaemia, but those with silent ischaemia were more likely to have had an inferior infarct than those with a negative exercise test $(63 \% v 43 \%, p=$ $0.01)$. Patients with symptomatic ischaemia were more likely $(57 \%)$ than both the silent $(34 \%)$ and the negative $(28 \%)$ test groups to have had a non- $Q$ wave infarction. 
Table 4 Silent ischaemia: a high risk subgroup

\begin{tabular}{|c|c|c|c|c|}
\hline & $\begin{array}{l}\text { Silent ischaemia } \\
\text { (higher risk) } \\
(18)\end{array}$ & $\begin{array}{l}\text { Silent ischaemia } \\
\text { (lower risk) } \\
\text { (46) }\end{array}$ & $\begin{array}{l}\text { Symptomatic } \\
\text { ischaemia } \\
\text { (37) }\end{array}$ & $\begin{array}{l}\text { Negative exercise } \\
\text { test } \\
\text { (113) }\end{array}$ \\
\hline $\begin{array}{l}\text { Dead at } 1 \text { year } \\
\text { (no, ".") } \\
\text { Relative odds } \\
\text { CABG *(no," } \\
\text { Relative odds }\end{array}$ & $\begin{aligned} 4 & (22) \\
32 & \\
4 & (22) \\
10 & \end{aligned}$ & $\begin{array}{l}2 \\
5 \cdot 1 \\
5 \\
4 \cdot 5\end{array}$ & $\begin{array}{ll}2 & (5 \cdot 4) \\
6 \cdot 4 & \\
11 & (30) \\
16 & \end{array}$ & $\begin{array}{ll}1 & (0 \cdot 9) \\
1 & \\
3 & (2 \cdot 7) \\
1 & \end{array}$ \\
\hline
\end{tabular}

^No patient undergoing coronary artery bypass grafting (CABG) died in the first year. Three patients were lost to follow up.

Other exercise test variables (table 5)

Patients with symptomatic ST depression were less likely to complete the submaximal exercise test than patients with silent ischaemia. There were no significant differences in the distribution of the other exercise test variables. The absence of symptoms in the group with silent ischaemia could not be accounted for by a slower heart rate nor a different acceleration of heart rate nor by a lower double product.

Angiographic variables (table 5)

The groups with silent ischaemia and a negative test could not be distinguished by differences in the degree of left ventricular damage, number of vessels diseased, extent of coronary disease, or the degree of collateralisation.

\section{Discussion}

Silent ischaemia is of prognostic relevance in patients with asymptomatic, ${ }^{23} 24$ stable, ${ }^{2526}$ or unstable coronary artery disease.$^{27-29}$ Its importance after infarction is less clear. We found silent ischaemia, identified by means of a predischarge exercise test, in $27 \%$ of clinically stable patients after myocardial infarction. This accords with two other major studies: in one, silent ischaemia was identified in $23 \%$ of patients by means of an exercise test, ${ }^{8}$ and in the other ambulatory ST segment monitoring showed silent ischaemia in $29 \%$ of a higher risk group. ${ }^{14}$ We do not know, however, whether currently available therapeutic options can improve the prognosis of patients with silent ischaemia, whether or not this follows infarction. ${ }^{30}$

In our study, mortality was higher in patients with silent ischaemia than in those with a negative exercise test. The fact that patients with a positive exercise test were treated with a $\beta$ blocker before discharge but patients with a negative test were treated at the discretion of their referring physician is not likely to have confounded these results. It is unlikely that this treatment harmed the group with a positive exercise test because these drugs improve prog-

Table 5 Differences in clinical, ECG exercise test, and angiographic variables between groups

\begin{tabular}{|c|c|c|c|c|c|c|c|c|c|}
\hline & \multicolumn{2}{|c|}{$\begin{array}{l}\text { Silent } \\
(n=67)\end{array}$} & \multicolumn{2}{|c|}{$\begin{array}{l}\text { Symptomatic } \\
(n=37)\end{array}$} & \multicolumn{2}{|c|}{$\begin{array}{l}\text { Negative } \\
(n=123)\end{array}$} & \multicolumn{3}{|c|}{ Statistical analysis } \\
\hline & No & $(\%)$ & No & $(\%)$ & $\mathrm{No}$ & $(\%)$ & $\begin{array}{l}\text { Silent } \\
v \text { symptomatic }\end{array}$ & $\begin{array}{l}\text { Silent } \\
\text { v negative }\end{array}$ & $\begin{array}{l}\text { Symptomatic } \\
\text { v negative }\end{array}$ \\
\hline $\begin{array}{l}\text { History: } \\
\text { Male } \\
\text { Female } \\
\text { Previous MI } \\
\text { Smoker } \\
\text { Diabetes } \\
\text { Hypertension } \\
\text { + ve Family history }\end{array}$ & $\begin{array}{r}58 \\
9 \\
6 \\
58 \\
11 \\
17 \\
17\end{array}$ & $\begin{array}{r}(87) \\
(13) \\
(9) \\
(87) \\
(16) \\
(25) \\
(25)\end{array}$ & $\begin{array}{r}30 \\
7 \\
5 \\
30 \\
3 \\
6 \\
9\end{array}$ & $\begin{array}{l}(81) \\
(19) \\
(14) \\
(81) \\
(8) \\
(16) \\
(24)\end{array}$ & $\begin{array}{r}110 \\
13 \\
4 \\
94 \\
12 \\
13 \\
24\end{array}$ & $\begin{array}{l}(89) \\
(11) \\
(3) \\
(76) \\
(10) \\
(11) \\
(20)\end{array}$ & $\begin{array}{l}\text { NS } \\
\text { NS } \\
\text { NS } \\
\text { NS } \\
\text { NS } \\
\text { NS }\end{array}$ & $\begin{array}{l}\text { NS } \\
\text { NS } \\
\text { NS } \\
\text { NS } \\
\text { p= } 0.008 \\
\text { NS }\end{array}$ & $\begin{array}{l}\text { NS } \\
\text { NS } \\
\text { NS } \\
\text { NS } \\
\text { NS } \\
\text { NS }\end{array}$ \\
\hline $\begin{array}{l}\text { Site/type of MI: } \\
\text { Anteriort } \\
\text { Inferior }{ }^{\dagger} \\
Q \text { wave } \\
\text { Non-Q wave }\end{array}$ & $\begin{array}{l}23 \\
42 \\
44 \\
23\end{array}$ & $\begin{array}{l}(34) \\
(63) \\
(66) \\
(34)\end{array}$ & $\begin{array}{l}15 \\
21 \\
16 \\
21\end{array}$ & $\begin{array}{l}(41) \\
(57) \\
(43) \\
(57)\end{array}$ & $\begin{array}{l}65 \\
53 \\
89 \\
34\end{array}$ & $\begin{array}{l}(53) \\
(43) \\
(72) \\
(28)\end{array}$ & $\begin{array}{l}\text { NS } \\
p=0.03\end{array}$ & $\begin{array}{l}p=0.01 \\
\text { NS }\end{array}$ & $\begin{array}{l}\text { NS } \\
p=0.001\end{array}$ \\
\hline $\begin{array}{l}\text { Positive exercise test variables: } \\
\text { Inability to complete } \\
\text { Abnormal BP response } \\
\text { Ventricular arrhythmias } \\
\text { ST elevation } \\
\text { Mets when ST depression occurred: } \\
\leqslant 3 \\
4-5 \\
\leqslant 2 \mathrm{~mm} \text { of ST depression } \\
>2 \mathrm{~mm} \text { of ST depression } \\
<2 \mathrm{~min} \text { ECG recovery time } \\
2-5 \text { min ECG recovery time } \\
>5 \text { min ECG recovery time } \\
\text { Mean heart rate at rest (SD) } \\
\text { Mean heart rate at } 3 \text { min (SD) } \\
\text { Mean heart rate at } 6 \text { min (SD) } \\
\text { Mean rate diff } 3 \text { min - rest (SD) } \\
\text { Mean rate diff } 6 \text { min - rest (SD) }\end{array}$ & $\begin{array}{r}4 \\
14 \\
4 \\
28 \\
\\
40 \\
27 \\
55 \\
12 \\
7 \\
27 \\
33 \\
78 \\
112 \\
120 \\
34 \\
43\end{array}$ & $\begin{array}{l}(6) \\
(21) \\
(6) \\
(42) \\
\\
(60) \\
(40) \\
(82) \\
(18) \\
(10) \\
(40) \\
(49) \\
(18) \\
(21) \\
(22) \\
(12) \\
(13)\end{array}$ & $\begin{array}{r}7 \\
12 \\
3 \\
12 \\
18 \\
19 \\
19 \\
34 \\
3 \\
4 \\
17 \\
15 \\
73 \\
109 \\
116 \\
37 \\
44\end{array}$ & $\begin{array}{l}(19) \\
(32) \\
(8) \\
(32) \\
(49) \\
(51) \\
(92) \\
(8) \\
(11) \\
(47) \\
(41) \\
(13) \\
(25) \\
(18) \\
(22) \\
(17)\end{array}$ & & & $\begin{array}{l}\text { p }=0.04 \\
\text { NS } \\
\text { NS } \\
\text { NS } \\
\text { NS } \\
\text { NS } \\
\text { NS } \\
\text { NS } \\
\text { NS } \\
\text { NS } \\
\text { NS } \\
\text { NS } \\
\text { NS } \\
\text { NS }\end{array}$ & & \\
\hline $\begin{array}{l}\text { Angiographic variablesł: } \\
\text { 0 vessels diseased } \\
1 \text { vessel diseased } \\
2 \text { vessels diseased } \\
3 \text { vessels diseased } \\
4 \text { vessels diseased } \\
\text { Mean coronary artery score }(\text { SD) } \\
\text { Mean left ventricular score }(\text { SD) } \\
\text { Mean collateral score }(\text { SD) } \\
\text { Collateral score groups: } \\
\text { None (score } 0) \\
\text { Minor (score } 1,2) \\
\text { Major (score } 3,4)\end{array}$ & $\begin{array}{l}1 \\
19 \\
18 \\
16 \\
10 \\
21 \\
21 \\
2 \cdot 56 \\
13 \\
11 \\
40\end{array}$ & $\begin{array}{l}(1 \cdot 6) \\
(30) \\
(28) \\
(25) \\
(16) \\
(8 \cdot 4) \\
(5 \cdot 8) \\
(1 \cdot 56) \\
(20) \\
(17) \\
(63)\end{array}$ & $\begin{array}{l}1 \\
5 \\
12 \\
12 \\
4 \\
23 \\
19 \\
2 \cdot 97 \\
6 \\
2 \\
26\end{array}$ & $\begin{array}{l}(2 \cdot 9) \\
(15) \\
(35) \\
(35) \\
(12) \\
(8 \cdot 8) \\
(5 \cdot 8) \\
(1 \cdot 55) \\
\\
(18) \\
(5 \cdot 9) \\
(77)\end{array}$ & ) & & $\begin{array}{l}\text { NS } \\
\text { NS } \\
\text { NS } \\
\text { NS } \\
\text { NS } \\
\text { NS } \\
\text { NS }\end{array}$ & . & \\
\hline
\end{tabular}

$\chi^{2}$, but analysis of variance for means: only $p<0.05$ shown; NS, not significant. $\dagger$ Excluding those with new infarction in both territories. 
nosis after infarction ${ }^{31}$ and were not prescribed if there were contraindications. Mortality in patients with silent ischaemia $(9.4 \%)$ and symptomatic ischaemia $(5.4 \%)$ was not significantly different. Those with symptomatic ischaemia were more likely to undergo coronary artery bypass grafting-probably because they were more likely to have angina in the year after infarction. None of the patients undergoing operation died within the first year. Although it has never been formally tested in post-infarct patients, careful selection of patients for early revascularisation is likely to improve prognosis. ${ }^{32}$ Our results indicate that the absence of symptoms associated with silent ischaemia should not necessarily preclude patients from a revascularisation programme. Attempted revascularisation of all patients with silent ischaemia after infarction is, however, probably not desirable. ${ }^{33-35} \mathrm{~A}$ group of patients with silent ischaemia who were at particularly high risk was identified by ST segment depression during exercise accompanied by an abnormal blood pressure response or by the patient's inability to complete the submaximal exercise protocol. Mortality was $22 \%$ in this group. Although by no means forming a comparable group, the patients receiving placebo in the Coronary Drug Project (men who had survived to at least three months after infarction) had a first year mortality of about $5 \%$. Only those in the top three deciles of risk (based on 10 clinical characteristics) had a five year mortality greater than $22 \%{ }^{36}$ The benefit of therapeutic revascularisation in these patients should be studied in a much larger population. Our findings suggest that objective evidence of ischaemia after infarction should lead to further stratification and not simply be considered as a concept to "excite and reward underemployed cardiologists". ${ }^{37}$

The coronary arteriographic characteristics of the groups with silent ischaemia and symptomatic ischaemia were similar-indicating that symptoms are not caused by more widespread coronary disease, and confirming similar observations made by others. ${ }^{2438} 39$ The extent of left ventricular damage was also similar in the two groups and this factor does not account for the different mortalities. In the Coronary Artery Surgery Study, although patients with both angina and ST depression were somewhat more likely to have triple vessel disease than those with only one of these features, the long term outcome was similar in these three groups; outcome in each group was related to the number of diseased vessels. ${ }^{24}$ There are, however, major population differences between such a study and the present one in which only post-infarction patients were investigated.

No features of the previous clinical history helped to distinguish between those with silent ischaemia and those with symptomatic ischaemia. Patients with silent ischaemia, were, however, more likely to have a history of hypertension than patients with a negative exercise test. This difference may be partly explained by a higher incidence of abnormalities on the resting electrocardiogram in patients with a history of hypertension. In such patients further significant ST segment depression on exercise may simply represent an exercise induced exaggeration of an abnormality that is already present. Alternatively, these changes may indicate true ischaemia, reflecting patterns of coronary disease of small vessels or increased oxygen demands in hypertensive patients. An association between hypertension and the development of silent myocardial infarction has been noted before. ${ }^{4041}$ The group with silent ischaemia had a higher incidence of inferior infarction than either the symptomatic group or those with a negative exercise test. Since the 12 lead electrocardiographic exercise test is more sensitive for anterior than inferior ST segment depression, ${ }^{38}$ it may be that some patients with anterior infarcts but with residual inferior ischaemia are "missed" by the exercise test when ST segment depression is the only feature considered. Patients with symptomatic ischaemia were more likely to have had a non- $Q$ wave infarction than those with silent ischaemia (relative odds $2 \cdot 5: 1$ ) and patients with negative exercise tests were the least likely to have had a non-Q wave infarction.

There are particular difficulties in defining "ischaemia" on the exercise electrocardiogram soon after infarction. ST segment elevation in the territory of the infarct may become more pronounced on exercise, and if ST segment depression occurs in the electrocardiographic leads that represent the area opposite to this territory, it is impossible to be certain whether this is a reciprocal electrical event or represents true ischaemia. This is potentially important in the context of this study because the group with ST segment elevation might have a higher mortality related to more extensive left ventricular damage. Further analysis, however, showed that mortality was the same whether ST depression occurred alone or together with ST elevation. In addition, it might be argued that patients in whom dyspnoea develops in the presence of ST depression do not have "silent" ischaemia. But there are difficulties in objectively assessing the cause of dyspnoea in patients soon after infarction, and there are advantages in a simple definition of silent ischaemia that allows for comparison between studies.

Exercise testing after myocardial infarction is now recognised as a powerful means of risk stratification; it provides multiple variables some of which are more useful for predicting clinical outcome than others. ${ }^{16} \mathrm{We}$ found that those with ST depression, whether silent or not, have a higher mortality than those with a negative exercise test. Those patients in whom silent ischaemia is associated with an abnormal blood pressure response or who are unable to complete a submaximal protocol are at particular risk. Patients with symptoms of angina associated with the ST depression are currently more likely to undergo attempted revascularisation than those with silent ischaemia. Our results suggest that withholding therapeutic revascularisation from those with silent ischaemia, particularly the subgroups at higher 
risk, may be inappropriate. A study is needed to investigate the potential benefit of therapeutic revascularisation in high risk groups.

1 Colbeck EH. Angina pectoris: a criticism and a hypothesis. Lancet 1903;i:793-5.

2 Theroux P, Waters DD, Halphen C, Debaisieux JC, Mizgala HF. Prognostic value of exercise testing soon after myocardial infarction. $N$ Engl $J$ Med 1979;301: 341-5.

3 Amsterdam EZ, Martschinske R, Laslett LJ, Rutledge JC, Zakauddin V. Symptomatic and silent myocardial ischaemia during exercise testing in coronary artery disease. Am J Cardiol 1986;58:43B-6B.

4 Lindsey $\mathrm{HE} \mathrm{Jr}$, Cohn PF. "Silent" myocardial ischemia during and after exercise testing in patients with coronary during and after exercise testing in patients

5 Stern S, Tzivoni D. Early detection of silent ischaemic heart disease by 24 -hour electrocardiographic monitoring of disease by 24-hour electrocardiographic

6 Chiariello M, Indolfi C, Cotecchia MR, Sifola C, Romano $M$, Condorelli $M$. Asymptomatic transient ST changes during ambulatory monitoring in diabetic patients. Am Heart $J$ 1985;110:529-34.

7 Quyyumi AA, Wright C, Fox K. Ambulatory electrocardiographic ST segment changes in healthy volunteers. Br Heart J 1983;50:460-4.

8 Gibson RS, Beller GA, Kaiser DL. Prevalence and clinical significance of painless ST segment depression during early postinfarction exercise testing. Circulation 1987; 75(suppl II): 1136-9.

9 Rozanski A, Berman DS. Silent myocardial ischemia. I. Pathophysiology, frequency of occurrence, and approaches towards detection. Am Heart J 1987;114:615-26.

10 Mulcahy D, Keegan J, Crean P, et al. Silent myocardial ischaemia in chronic stable angina: a study of its frequency and characteristics in 150 patients. Br Heart $J$ 1988;60: and charac 23 .

11 Weiner DA, McCabe C, Hueter DC, Ryan TJ, Hood WB Jr. The predictive value of anginal chest pain as an indicator of predictive value of anginal chest pain as an indicator of coronary disease

12 Arnim ThV. Silent ischaemia in patients with coronary heart disease: prevalence and prognostic implications. Eur Heart $J$ 1987;8(suppl G):115-8.

13 Berliner U, Landry F, Jette $M$, Blumchen G. Silent ischaemia in post-infarction patients: a 21 -month followup study. Eur Heart J 1987;8(suppl G):131-5.

14 Gottlieb SO, Gottlieb SH, Achuff SC, et al. Silent ischemia on Holter monitoring predicts mortality in high-risk postinfarction patients. $J A M A 1988 ; 259: 1030-5$.

15 Stevenson WG, Linssen GCM, Havenith MG, Brugada $P$, Wellens HJJ. Late death after myocardial infarction: mechanisms, etiologies, and implications for sudden
death. In: Brugada P, Wellens HJJ, eds. Cardiac arrhythmias: where to go from here? Mount Kisco, New York: Futura Publishing Company, 1987:377-89.

16 de Belder MA, Pumphrey CW, Skehan JD, et al. Relative power of clinical, exercise test, and angiographic variables the Newham and Tower Hamlets study. Br Heart J 1988; 60:377-89.

17 Principal Investigators of CASS and their associates. The National Heart, Lung, and Blood Institute Coronary Artery Surgery Study (CASS). Circulation 1981;63(suppl I):I1-81

18 CASS Principal Investigators and their Associates. Coronary Artery Surgery Study: a randomised trial of coronary artery bypass surgery. Survival data. Circulation 1983; 68:939-50.

19 European Coronary Surgery Study Group. Prospective randomized study of coronary bypass surgery in stable angina pectoris. Lancet 1980;ii:491-5.

20 Sackett DL, Haynes RB, Tugwell P. Clinical epidemiology. $A$ basic science for clinical medicine. Boston and Toronto: Little, Brown and Company, 1985.

21 Sullivan ID, Davies DW, Sowton E. Submaximal exercise testing early after myocardial infarction. Prognostic importance of exercise induced ST segment elevation. $B$ Heart J 1984;52:147-53.

22 Lahiri A, Balasubramanian V, Millar Craig MW, Crawley J, Raftery EB. Exercise-induced ST segment elevation. Electrocardiographic, angiographic, and scintigraphic evaluation. Br Heart J 1980;43:582-8.

23 Cohn PF. Prognosis and treatment of asymptomatic coronary artery disease. J Am Coll Cardiol 1983;1:959-64.

24 Weiner DA, Ryan TJ, McCabe $\mathrm{CH}$, et al. Significance of silent myocardial ischemia during exercise testing in patients with

25 Cole JP, Ellestad MH. Significance of chest pain during treadmill exercise: correlation with coronary events. $A m \mathrm{~J}$ treadmill exercise: correl

26 Cohn PF. Silent myocardial ischemia: classification prevalence, and prognosis. Am J Med 1985;79(suppl prevalence,

27 Gottlieb SO, Weisfeldt ML, Ouyang P, Mellits ED Gerstenblith $G$. Silent ischemia predicts infarction and death during 2 year follow-up of unstable angina. $J A m$ Coll Cardiol 1987;10:756-60.

28 Johnson SM, Mauritson DR, Winniford MD, et al. Continuous electrocardiographic monitoring in patients with unstable angina pectoris: identification of high-risk subgroup with severe coronary disease, variant angina, and/o impaired early prognosis. Am Heart J 1982;103:4-12.

29 Nademanee K, Intarachot V, Josephson MA, Rieders D, Mody FV, Singh BN. Prognostic significance of silen myocardial ischemia in patients with unstable angina. Am Coll Cardiol 1987;10:1-9.

$30 \mathrm{Fox}$ KM. Silent ischaemia: clinical implications in 1988. $\mathrm{Br}$ Heart J 1988;60:363-6.

31 Yusuf S, Peto R, Lewis J, Collins R, Sleight P. Beta blockade during and after myocardial infarction: an overview of the randomized trials. Prog Cardiovasc Dis 1985;XXVII: random

32 Akhras F, Upward J, Keates J, Jackson G. Early exercise testing and elective coronary artery bypass surgery after uncomplicated myocardial infarction. Effect

33 Selzer A, Cohn K. Asymptomatic coronary artery disease and coronary bypass surgery. Am J Cardiol 1977;39. 614-6.

34 Resnekov L. Silent myocardial ischemia: therapeutic implications. Am J Med 1985;79(suppl 3A):30-4

35 Epstein SE, Quyyumi A, Bonow RO. Current concepts myocardial ischemia-silent or symptomatic. $N$ Engl Med 1988;318:1038-43.

36 Schlant RC, Forman S, Stamler J, Canner PL. The natural history of coronary heart disease: prognostic factors after recovery from myocardial infarction in 2789 men. The 5 year findings of the Coronary Drug Project. Circulation 1982;66:401-14.

37 Anonymous. Total ischaemic burden. Lancet 1987;i:424-5.

38 Castellanet MJ, Greenberg PS, Ell of $S-T$ segment changes on exercise testing with angiographic findings in patients with prior myocardial infarcgraphic findings in patients with
tion. Am J Cardiol 1978;42:29-35.

39 Ouyang P, Shapiro EP, Chandra NC, Gottlieb SH, Chew PH, Gottlieb SO. An angiographic and functional comparison of patients with silent and symptomatic treadmill parison of patients with silent and symptomatic treadmill ischemia early

40 Medalie JH, Goldbourt U. Unrecognised myocardial infarction: five-year incidence, mortality, and risk factors. $A n n$ Intern Med 1976;84:526-31.

41 Kannel WB, Dannenberg AL, Abbott RD. Unrecognized myocardial infarction and hypertension. The Framing ham Study. Am Heart J 1985;109:581-5. 